\title{
Microgrid Islanding Detection Based on Mathematical Morphology
}

\author{
Fatemeh Ghalavand ${ }^{1}$, Behzad Asle Mohammadi Alizade ${ }^{1}$, Hossam Gaber 2,* \\ and Hadis Karimipour ${ }^{3}$ (D) \\ 1 Department of Electrical Engineering, Shahid Beheshti University, Tehran 1983969411, Iran; \\ f_ghalavand@sbu.ac.ir (F.G.); Alizadeh.be@gmail.com (B.A.M.A.) \\ 2 Faculty of Engineering and Applied Science, University of Ontario Institute of Technology, Oshawa, \\ ON L1H 7K4, Canada \\ 3 School of Engineering, University of Guelph, Guelph, ON N1G 2W1, Canada; hkarimi@uoguelph.ca \\ * Correspondence: hossam.gaber@uoit.ca; Tel.: +1-(519)-824-4120 (ext. 52506)
}

Received: 12 September 2018; Accepted: 5 October 2018; Published: 10 October 2018

check for updates

\begin{abstract}
Voltage and frequency stability are highly important for reliable performance of smart grids. In grid-connected mode, the utility controls these parameters, but when islanding occurs these parameters exceed their limits, which may result in irreparable damage to the system. This paper presents a time-domain approach which uses basic mathematical morphology (MM) operators, dilation and erosion filters, for microgrid islanding detection. The proposed method applies a dilation-erosion differential filter (DED) of the RMS signal (DEDFOR) at the point of common coupling (PCC) in a micro-grid connected to distributed generations (DGs). To evaluate the performance of the proposed approach, it is tested and compared with existing techniques in the literature under various conditions such as capacitor bank switching and motor starting. The results verify the accuracy and efficiency of the proposed technique for islanding detection under different operating conditions and various power mismatches.
\end{abstract}

Keywords: microgrid; islanding detection; dilation-erosion differential filter of RMS signal; mathematical morphology; passive method; signal processing method

\section{Introduction}

The rapid integration of smart grid (SG) technology opens up the possibility to aggregate microgrids into the electrical power system and to improve power quality in a safe and reliable manner [1,2]. Microgrids as integral parts of SG, can be viewed as small-scale power systems with self-supply capability [3]. According to the U.S. Department of Energy [4], a microgrid is a group of interconnected loads that is often composed of distributed energy resources (DERs) [5], distributed generations (DGs), flexible loads, and energy storage systems (ESSs) with the ability to connect and disconnect from the grid to operate in both grid-connected and islanded mode [6,7].

DGs are small-scale power generations, which are a promising solution to the economic and environmental issues of conventional power systems [8,9]. Integration of DGs and other DERs, i.e., wind energy, solar energy, and hydraulic energy, into the traditional electric power system, can reduce the emission of the greenhouse gases, and solve the environmental issues [10].

Reliable performance of microgrids, which are the heart of smart grid technology, depends on the microgrids' operational conditions and protection systems. Despite the positive impacts of microgrids, they bring many technical challenges for the safe operation, protection, and stability of the power grid [11]. Compared to traditional grids, distribution systems have different operating characteristics, such as bidirectional power flow, voltage profile fluctuations, and possible occurrence of islanding [12]. 
Following a disturbance in a power system, the main breaker may be opened automatically to isolate faults. An islanding condition occurs when a power supply from the main utility is interrupted, but the microgrid keeps supplying power into the distribution networks. Unintentional islanding due to grid faults or wrong circuit breaker operations may result in low power-quality, overload conditions, equipment damage, and even safety hazards [13-15]. Therefore, it is necessary to effectively detect the islanding conditions and swiftly disconnect microgrid from the distribution network within a specified time interval. The design and control requirements required for the safe islanding of a realistic microgrid along with an organized approach for improving the economic, reliable and secure operation of microgrids operating either in the on-grid or in the off-grid is investigated in $[16,17]$.

The microgrid has reduced system inertia due to increased penetration of non-synchronous generation sources (e.g., storage devices, wind power and solar photovoltaic) resulting in increased risk of frequency instability [18]. Therefore, the conventional methods fail to detect islanding condition and small changes at the point of common coupling (PCC) for distribution systems. To mitigate the risk, the corresponding IEEE standards specify the requirements for islanding detection and prevention to be implemented within microgrid equipment [18]. Table 1 shows some common standards for islanding detection, voltage and frequency ranges, along with the required detection time.

Table 1. Common standards for islanding detection.

\begin{tabular}{cccc}
\hline Standards & Detection Time & Frequency Range & Voltage Range \\
\hline IEEE-1547 [19] & $\mathrm{t}<2 \mathrm{~s}$ & $49.3 \mathrm{~Hz} \leq f \leq 50.5 \mathrm{~Hz}$ & $0.88 \leq \mathrm{V} \leq 1.1 \mathrm{p} . \mathrm{u}$ \\
\hline IEEE-929-2000 [20] & $\mathrm{t}<2 \mathrm{~s}$ & $49.3 \mathrm{~Hz} \leq f \leq 50.5 \mathrm{~Hz}$ & $0.88 \leq \mathrm{V} \leq 1.1 \mathrm{p} . \mathrm{u}$ \\
\hline IEC-62116 [21] & $\mathrm{t}<2 \mathrm{~s}$ & $48.5 \mathrm{~Hz} \leq f \leq 51.5 \mathrm{~Hz}$ & $0.85 \leq \mathrm{V} \leq 1.15 \mathrm{p} . \mathrm{u}$ \\
\hline
\end{tabular}

In this work, the standards shown in Table 1 is used to evaluate the performance of the proposed method in the non-detection zone (NDZ) of the UV/OV and UF/OF relays. Islanding detection methods can be classified into two major approaches: remote and local detection techniques [22]. Remote detection methods are communication-based techniques which mainly operate based on transferring data/signals between the electric utility and the DG units. Communication-based methods such as remote-end measurement $[23,24]$ and wide-area phasor estimation $[25,26]$ that rely on real-time data transmission are highly expensive and might cause relay malfunction due to communication failures. Local methods monitor the changes in the system's parameters. These techniques can be further divided into three main subgroups: active, passive and hybrid methods. Active techniques are based on intentional transients or harmonic effects. These methods usually inject a perturbation into the system and monitor the output power variations, active frequency drifts, and phase of the voltage at a point of common coupling (PCC) in islanding mode [27]. The dominant active techniques includes active frequency drift (AFD) [28], second harmonic drift [29], frequency jump [30], locking frequency band [31], active frequency drift with positive feedback [32], high frequency signal injection [33], and current injection [34,35]. Despite their effectiveness in islanding detection, active techniques need to continuously vary the DG output, which negatively affects power quality (PQ) and speed of detection while compromising the reliability of islanding detection at the PCC. Additionally, disturbance injection may affect the system reliability.

Passive methods detect islanding conditions by monitoring the system parameters. Under/over voltage (UV/OV) and under/over frequency (UF/OF) methods are examples of passive techniques which monitor changes in the frequency and voltage to identify islanding condition [36,37]. To improve the detection performance, more sensitive indicators such as power spectral density [38], and frequency-dependent impedance change [39] have been proposed. The main drawback associated with passive techniques is their large non-detection zone (NDZ) which results in their failure when there is a small power mismatch between DG and the load. 
To reduce the non-detection zone (NDZ) in passive techniques spectral decomposition and advanced filtering techniques including wavelet singular entropy [40], artificial neural network [41], Goertzel algorithm based on discrete Fourier transform [27], pattern recognition [42], and data mining [43] were developed. However, these methods require time-consuming data-training processes as opposed to an analytic model that characterizes the actual physical interconnection topology.

Hybrid methods which are a combination of the previous techniques are developed to overcome the abovementioned drawbacks [44]. These approaches mainly use passive techniques to detect islanding conditions and switch to active methods in the case of small changes in the system parameters. Recent literature that focuses on hybrid islanding detection techniques can be found in [45-47]. Although these methods have their advantages, they are usually time consuming and costly, which makes their real implementation infeasible.

Overall, islanding phenomena are still one of the technical barriers for widespread deployment of microgrids. Researchers are still struggling to develop highly precise and fast techniques that can adapt to the dynamic nature of microgrid technology.

In this paper, a novel islanding detection method is developed and tested on a microgrid with doubly-fed induction generators (DFIGs) as a case study. The proposed method is based on a differential morphological filter which relies on signal processing in order to detect the islanded condition during low active and reactive power mismatches. Compared to the existing techniques in the literature, the proposed method has smaller NDZ, faster detection time and higher accuracy.

Utilizing mathematical morphology (MM) different features of the high-frequency signals caused by power system disturbances are extracted to distinguish between normal and islanding conditions with high accuracy. The proposed method uses simple math operators which have low computational burden compared to matrix product, matrix inversion or other complicated mathematical operations. In addition, it does not need huge data transfer and the only data that we need to collect, and transfer is $V_{p c c}$ which is already measured in the system for other purposes. Therefore, it can efficiently detect islanding conditions within a short time interval. Simulation results on the various loads with different active and reactive power mismatches, compared with other islanding detection techniques, demonstrate the efficiency and accuracy of the proposed methods under different operation conditions with reduced NDZ.

The rest of the paper is organized as follows: in Section 2 the DFIG model is described. Mathematical morphology concept is discussed in Section 3. Section 4 presents the proposed algorithm. Case studies and simulation results are presented in Section 5 followed by our conclusions in Section 6 .

\section{DFIG Modeling}

The mechanical power extracted from wind turbine can be calculated as follows [48]:

$$
P_{\text {wind }}=\frac{1}{2} \rho \cdot\left(\pi r^{2}\right) \cdot V_{w}^{2}
$$

where $\rho$ and $V_{W}$ are air density and wind speed, respectively. $r$ refers to the radius of the turbine blades. According to Betz theory, the power can be exchanged to electrical energy by the following equation:

$$
\begin{gathered}
P_{\text {Extracted }}=C_{P} \times P_{\text {Wind }} \\
C_{p}(\lambda, \beta)=C_{1}\left(C_{2} / \lambda_{i}-C_{3} \beta-C_{4}\right) \cdot e^{-C_{5} / \lambda_{i}} \\
\lambda=\frac{r \omega_{m}}{V_{w}}
\end{gathered}
$$

where $C_{P}$ is the turbine power coefficient which is a function of the tip-speed ratio $\lambda$ and the turbine blade pitch angle $\beta . C_{1}=0.5, C_{2}=116, C_{3}=0.4, C_{4}=5, C_{5}=21$ and $\lambda_{i}=\left(\frac{1}{\lambda}-0.035\right)^{-1}$ [43]. 
Figure 1 shows $\lambda$ (turbine speed)-power for various wind speed and $\beta=0$ degree. It can be seen with beta $=0$, maximum power occurs at $9 \mathrm{~m} / \mathrm{s}$.

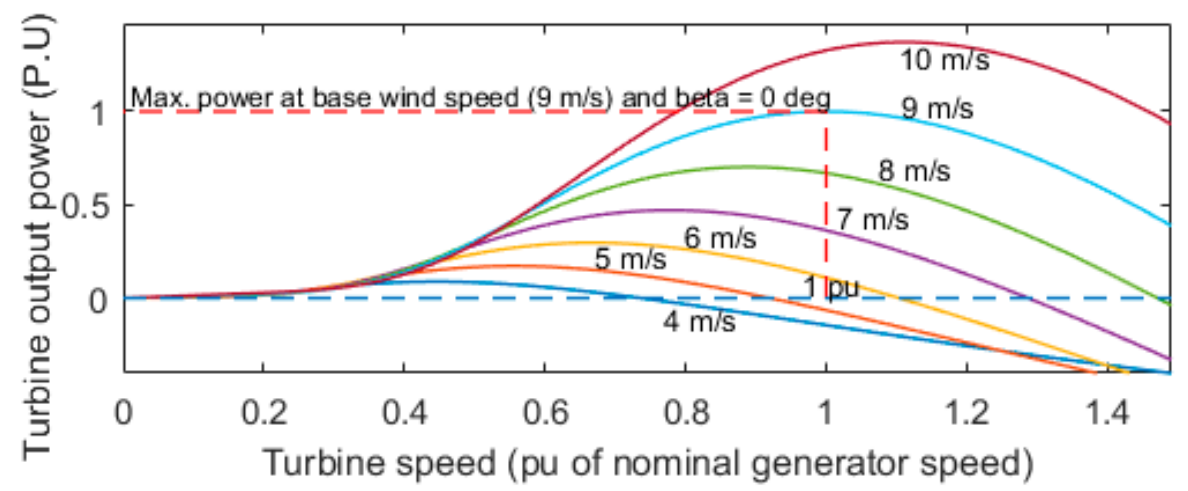

Figure 1. Turbine power characteristics (pitch angle beta $=0 \mathrm{deg}$ ).

As seen in Figure 1, there exists one single optimal $\lambda$ value, which corresponds to the maximum captured wind power for specific wind speed. In this paper, this optimal $\lambda$ is assumed to be known beforehand.

A block diagram for DFIG and its controller is shown in Figure 2, where two controllers connect the DFIG to the grid. Stator terminal of the DFIG is linked with a grid side converter (GSC) via a LCL filter and transformer, which generates converter current $i_{\text {gsc }}$. A DC-link capacitor is between both converters to connect GSC to rotor side converter (RSC) with rotor current $i_{r}$. A PWM structure is used to control GSC and RSC with active/reactive power and other line parameters. These back to back controllers keep the DC-link voltage $\left(\mathrm{V}_{\mathrm{dc}}\right)$ constant.

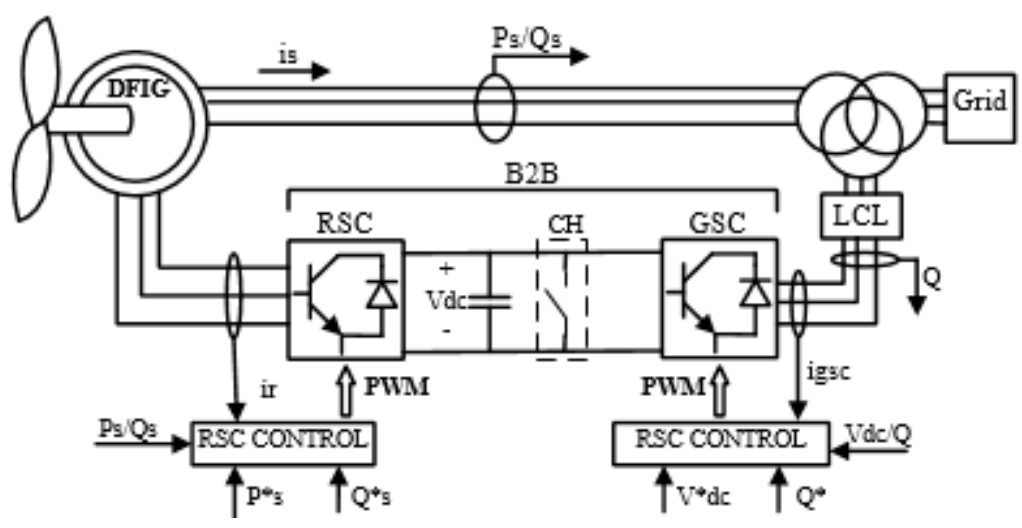

Figure 2. DFIG structure with the controllers.

\section{Overview of Mathematical Morphology}

Mathematical morphology is a time domain nonlinear signal processing technique which can be used to extract pertinent features of the signal under study [49]. It has a time domain structure with easier implementation, light computation and memory requirements compared to other signal processing techniques used for islanding detection. The feature extraction is based on the interaction between the original data set and another set, which is called a structuring element (SE). The main operators used in MM are addition and subtraction operators, thereby it is a fast and computationally inexpensive technique.

MM includes two basic morphological operators: dilation and erosion. Other hybrid operators like opening, closing, hit or miss and top-hat transform are defined based on these two operators. Dilation, erosion, opening, and closing are mostly used in power systems analysis. Proper SE selection 
can play an important role for efficient signal processing through MM. SE can be defined in different shapes such as flat, square, curve and triangular. In the power system analysis where the signals are one dimensional, a flat SE such as a single row or column is more suitable [50].

\subsection{Dilation and Erosion}

For a one-dimensional signal $\{x(n)\}$, with domain $D_{x}=\{0,1, \ldots, N-1\}$, where $N$ is the maximum value or the domain of values for the signal. We denote symmetric structuring element as $\{g(m)\}$, with domain $D_{g}=\{0,1, \ldots, M-1\}, M$ is the length of $\{g(m)\}$. In addition, $(M<N)$ so $x(n)$ is larger than $g(m)$. Then, the dilation of signal $x$ by $g$, denoted by $(x \oplus g)$ and erosion of signal $x$ by $g$, denoted by $(x \ominus g)$, are defined as:

$$
\begin{gathered}
x_{d}(n)=(x \oplus g)(n)=\max \{x(n-m)+g(m)\} \\
\quad \text { for } 0 \leq(n-m) \leq n, m \geq 0
\end{gathered}
$$

As an example, consider $n_{1}$ as the first sample where $n_{1} \in D x$. We will use $g(m)$ to consider a window of signal and find the maximum value in this window:

$$
\begin{aligned}
x_{d}\left(n_{1}\right)= & \max \left\{x\left(n_{1}-m_{1}\right)+g\left(m_{1}\right), x\left(n_{1}-m_{2}\right)+g\left(m_{2}\right), x\left(n_{1}-m_{3}\right)\right. \\
& \left.+g\left(m_{3}\right), \ldots, x\left(n_{1}-m_{M-1}\right)+g\left(m_{M-1}\right), x\left(n_{1}-m_{M}\right)+g\left(m_{M}\right)\right\}
\end{aligned}
$$

This process will be performed for all samples $(n=N)$. Every signal sample should also follow the Erosion relationship as:

$$
\begin{gathered}
x_{e}(n)=(x \ominus g)(n)=\min \{x(n+m)-g(m)\} \\
\text { for } 0 \leq(n+m) \leq n, m \geq 0
\end{gathered}
$$

Like the previous equation, for the first sample $n_{1}$, we can write:

$$
\begin{aligned}
x_{e}\left(n_{1}\right)= & \min \left\{x\left(n_{1}+m_{1}\right)-g\left(m_{1}\right), x\left(n_{1}+m_{2}\right)-g\left(m_{2}\right), x\left(n_{1}+m_{3}\right)\right. \\
& \left.-g\left(m_{3}\right), \ldots, x\left(n_{1}+m_{M-1}\right)-g\left(m_{M-1}\right), x\left(n_{1}+m_{M}\right)-g\left(m_{M}\right)\right\}
\end{aligned}
$$

where $n \in D x$ and $m \in D g . x_{d}(n)$ and $x_{e}(n)$ are the dilated and erotisted outputs of the signal $x(n)$ processed by $g(m)$ as SE, respectively. These values will be collected and plotted as a new signal which highlight the changes in the original signal and can be sued for islanding detection with high accuracy and efficiency.

\subsection{Opening and Closing}

Based on the two operations described in Equations (5) and (6), two other operators, opening and closing operators, can be defined. The opening operation of $x$ by $g$, denoted by $x \circ g$ and the closing operation of signal $x$ by $g$, denoted by $x \cdot g$ are defined as follows:

$$
\begin{aligned}
& x_{0}(n)=(x \circ g)(n)=((x \ominus g) \oplus g)(n) \\
& x_{c}(n)=(x \cdot g)(n)=((x \oplus g) \ominus g)(n)
\end{aligned}
$$

where $x_{o}(n)$ and $x_{c}(n)$ are the opening and closing outputs of the signal $x(n)$ processed by $g(m)$ as SE, respectively. In the following section a modified MM-based approach is used in this paper to detect islanding condition in power distribution systems.

\section{Proposed Islanding Detection Method}

The proposed method combines dilation and erosion operators in $\mathrm{MM}$ as a dilation-erosion differential (DED) filter to process the voltage signal at PCC for islanding detection. The goal of the proposed filter is to highlight the changes of the signal, so it can be easily detected in islanding condition. A flat SE $(g(m)=[0.1,0.1,0.1,0.1,0.1])$ is defined to extract the transient from the signal 
(PCC voltage in this work). The height of all elements in SE is considered equal to extract the transient from the voltage signal. Otherwise, it will result in unexpected complexity which may not be practical.

This also reduces the time delay for data transfer as the data is already in the measurement system $m_{d}$ and $m_{e}$ refer to the length of the SE for the dilation and erosion, respectively. To modify the MM algorithm for islanding detection a dilation-erosion differential filter (DEDF) is proposed as follows:

$$
\operatorname{DEDF}(n)=[(x \oplus g)(n)-(x \ominus g)(n)]
$$

DEDF is proposed to highlight the changes in the signal. To improve accuracy and further highlight changes in a signal. The result of a sample signal filtered by proposed DEDF is shown in Figure 3. Figure $3 b$ shows the output of the proposed filter applied on a sample signal shown in Figure 3a. As can be seen DEDF highlight the changes in the signal.

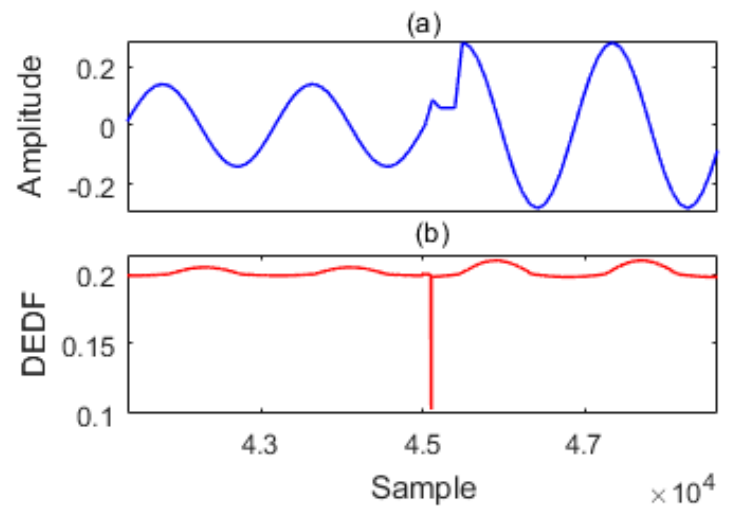

Figure 3. A sample signal analyzed by DEDF. (a) Sample signal as input of the DEDF; (b) output of the DEDF.

As can be seen from the figure, DEDF processes the signal to find sudden changes and fluctuations. These changes are then highlighted in the output of the DEDF. Therefore, it can be detected easily within a short time interval.

The proposed DEDF is applied on RMS of the signal (DEDFOR) which can be described as follows:

$$
\begin{gathered}
\operatorname{DEDFOR}(n)=\left[\left(x_{r} \oplus g\right)(n)-\left(x_{r} \ominus g\right)(n)\right] \\
\operatorname{DEDFOR}(n)=\left(x_{d r}-x_{e r}\right)(n)
\end{gathered}
$$

Using RMS signal behind the DED filter increases the accuracy of the filter under minor changes in the power network/microgrids. Therefore, in this paper, RMS of voltage signals is used as a basic signal $\left(x_{r}(n) \rightarrow x(n)\right)$. In addition, to avoid zero output in case of small changes in PCC signals, different lengths of SEs are selected for dilation and erosion. Aside from islanding conditions, there are other load behaviors in the system that can affect the PCC voltage. To avoid false alarms, the threshold is set based on the historical data collected from different operation conditions and by trial and error. The proposed algorithm will detect islanding conditions if the output of DEDFOR is higher than the predefined threshold. From the results reported in this work, which are collected under different operation conditions and scenarios, it can be seen that the proposed threshold works properly. The proposed algorithm is adaptive and will adjust the threshold value for different power system condition. Figure 4 shows the flowchart of the proposed algorithm.

At first, RMS value of phase voltages $(\mathrm{Va}, \mathrm{Vb}, \mathrm{Vc})$ of the feeders are extracted. The changes in all three phase voltages are compared with the threshold of the relay. If relays cannot detect the changes, DEDF starts a survey to detect the islanding condition. All signals are processed through the proposed DEDF to extract details of the signals. If the processed signal exceeds the threshold value, the algorithm will detect the islanding condition. In other word, in case of islanding condition, the magnitude of the 
voltage signals will increase which results in the increase in the output of DEDFOR. The algorithm stops once all samples of data are processed. These steps attempt to highlight unusual changes in the signal to distinguish between islanding condition and other events.

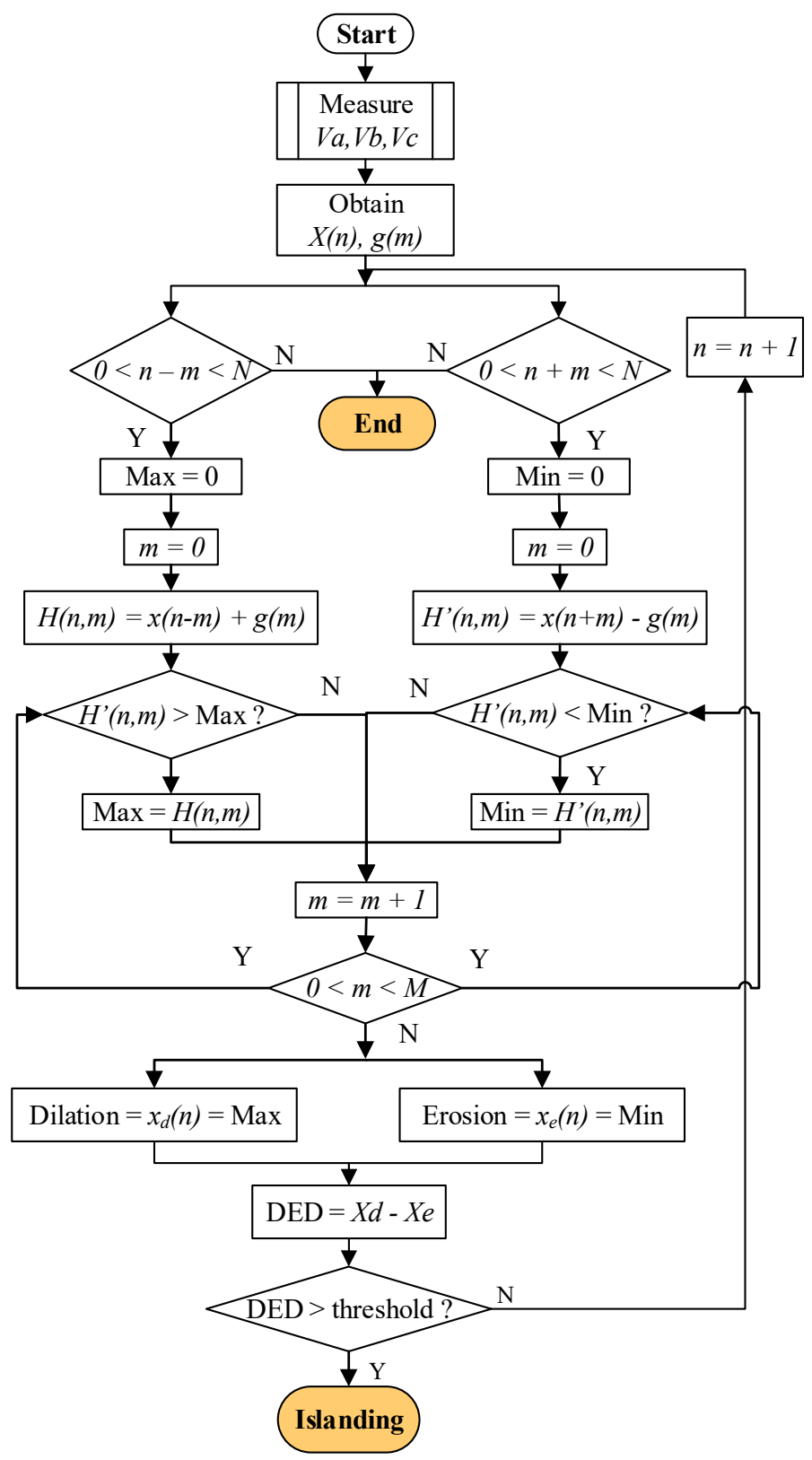

Figure 4. Flowchart of the proposed algorithm.

\section{Simulation Results}

In this section several case studies and operation condition are analyzed to verify the performance of the proposed algorithm in terms of detection time and non-detection zone (NDZ).

\subsection{Test System}

The test system used in this work is a balanced system with $50 \mathrm{~Hz}$ frequency depicted in Figure 5 . It can connect to various types of DGs, namely AC and DC sources via suitable converters. In this work, the network is linked to two wind turbines as the DFIG type with 9 MVA power consisting of six $1.5 \mathrm{MW}$. The grid is $120 \mathrm{kV}$ with 50 MVA power and connects to a $120 \mathrm{kV} / 25 \mathrm{kV}$ transformer. 
From PCC, an especial $25 \mathrm{kV}$ network supply with two DFIGs. The DFIGs are connected to the $25 \mathrm{kV}$ network using the transformers of rating $25 \mathrm{kV} / 575 \mathrm{~V}$ and $12 \mathrm{MVA}$ power. Various series and parallel loads with independent active/reactive power consumption are considered. All elements are connected to each other with 3-phase PI section lines with $10 \mathrm{~km}$ length. More details about the system are provided in Table 2.

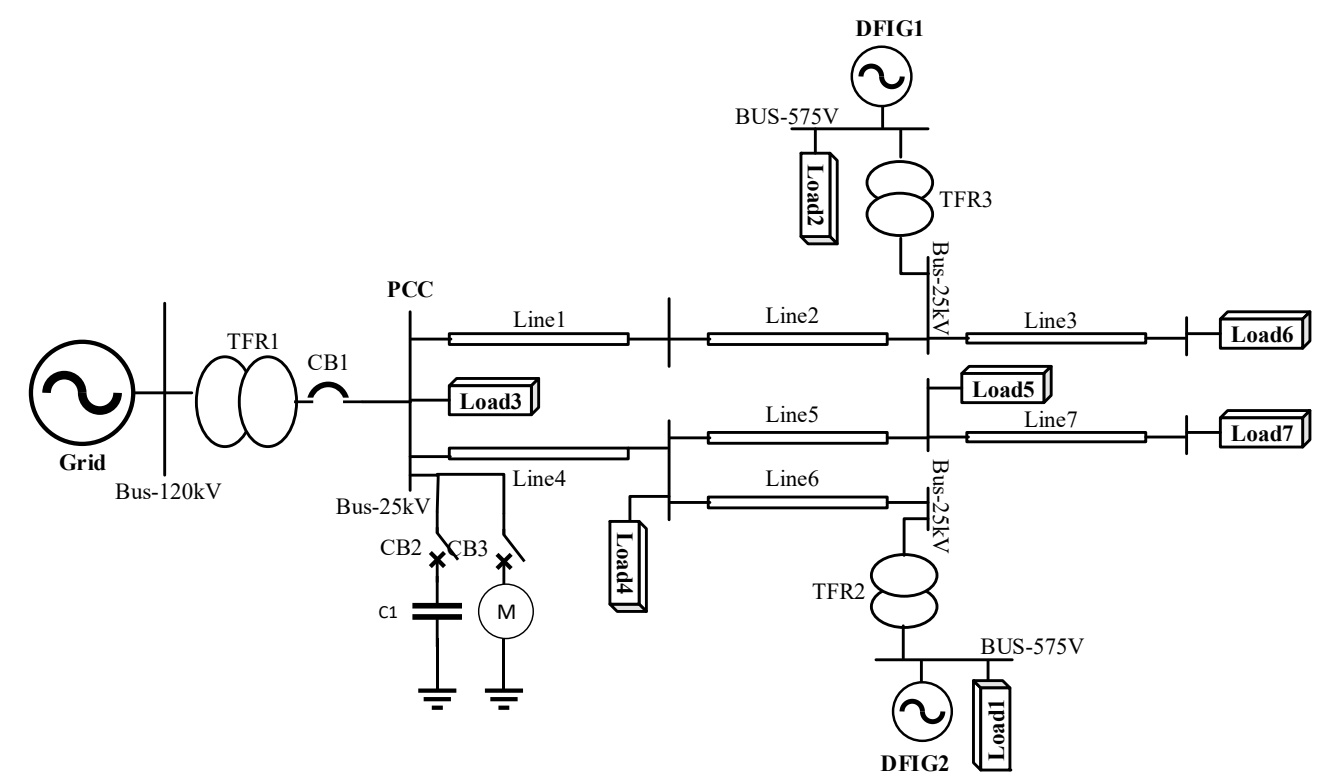

Figure 5. Schematic of the microgrid multiple DGs connected to the grid; Bus: bus bar.

Table 2. System parameters.

\begin{tabular}{cc}
\hline Grid & Transformer: TFR1 \\
\hline $120 \mathrm{kV}, 50 \mathrm{~Hz}$ & Side1: Yg; Side2: $\Delta$ \\
DGs: DFIG1,2 & $50 \mathrm{MVA}, 120 \mathrm{kV} / 25 \mathrm{kV}$ \\
9 MW, $575 \mathrm{~V}, 50 \mathrm{~Hz}$ & $R_{1}=R_{2}=0.08 / 30 \mathrm{p} \cdot \mathrm{u}, R_{m}=L_{m}=500 \mathrm{p} . \mathrm{u}$ \\
Lines: Line 1, 2, 3, 4, 5, 6,7 & $L_{1}=L_{2}=0.08 \mathrm{p} . \mathrm{u}$ \\
$50 \mathrm{~Hz}, 10 \mathrm{~km}$ & Transformer: TFR2,3 \\
3 phase pi section & Side1: $\Delta ;$ Side2: Yg \\
$R_{1}=0.1153, R_{0}=0.413(\mathrm{ohm} / \mathrm{km})$ & $12 \mathrm{MVA}, 25 \mathrm{kV} / 575 \mathrm{~V}$ \\
$L_{1}=1.05 \times 10^{-3}, L_{0}=3.32 \times 10^{-3}(\mathrm{H} / \mathrm{km})$ & $R_{1}=R_{2}=0.025 / 30 \mathrm{p} \cdot \mathrm{u}, R_{m}=500 \mathrm{p} . \mathrm{u}$ \\
$C_{1}=11.33 \times 10^{-9}, C_{0}=5.01 \times 10^{-9}(\mathrm{~F} / \mathrm{km})$ & $L_{1}=L_{2}=0.025 \mathrm{p} \cdot \mathrm{u}, L_{m}=\mathrm{Inf}$ \\
\hline
\end{tabular}

The power balance in the Figure 5 can be written as follows:

$$
\begin{gathered}
\sum_{i=1}^{n} P_{\text {Loadi }}+\Delta P=\sum_{i=1}^{n} P_{D G i} \\
\sum_{i=1}^{n} Q_{\text {Loadi }}+\Delta Q=\sum_{i=1}^{n} Q_{D G i} \\
S_{\text {Load }}=V_{p c c}{ }^{2} / Z_{L}^{*}=P_{\text {Load }}+\mathrm{j} Q_{\text {Load }} \\
P_{\text {Load }}=\operatorname{Real}\left(V_{p c c^{2}} / Z_{L}^{*}\right) \\
Q_{\text {Load }}=\operatorname{Imag}\left(V_{p c c}{ }^{2} / Z_{L}^{*}\right)
\end{gathered}
$$

where $P_{\text {Load }}$ and $P_{D G}$ are active power of loads and DGs, respectively. $\Delta P$ refers to power difference between loads and DG sources which is compensated by the network in connected mode. $Q_{\text {Load, }}$ 
$Q_{D G}$ and $\Delta Q$ are reactive power of loads, DGs, and reactive power difference between loads and DG sources, respectively.

In this work, islanding condition is simulated by opening the circuit breaker (CB1) that is near to the PCC. In this situation, both $P_{\text {net }}$ and $Q_{\text {net }}$ become zero so DGs should supply all available local loads individually. To verify the performance of the proposed method, it is tested and simulated under six different conditions.

\subsection{Case 1: Islanding}

In this case study, the assumption is that CB1 is opened due to a sudden fault in the upstream network at $t=0.5 \mathrm{~s}$. Therefore, the utility stops supplying loads and switches to the island mode. According to Equations (12) and (13), DGs support all of the load consumption without power transmission between the DGs and grid $\left(P_{\text {net }}, Q_{\text {net }}=0\right)$ in islanding mode. As can be seen in Equations (17) and (18), the voltage at PCC depends not only on active power but also on reactive power whereas load impedance is constant. Therefore, three phase voltages at the PCC are measured and processed using the proposed DEDFOR algorithm to detect islanding change in a power network.

As can be seen from Figure $6 a, b$, the voltage and frequency in the PCC does not change significantly before and after islanding, respectively. As previously mentioned in Table 1, over/under voltage and frequency relays operate only in a specific range. Therefore, the relays could not detect island in most sensitive conditions like this case. Utilizing the proposed DEDFOR, changes in the signal are magnified for islanding detection. As it is shown in Figure $6 c$, immediately after islanding happens at $0.5 \mathrm{~s}$, output of the DEDFOR passes the threshold and detects islanding condition less than $17 \mathrm{~ms}$.
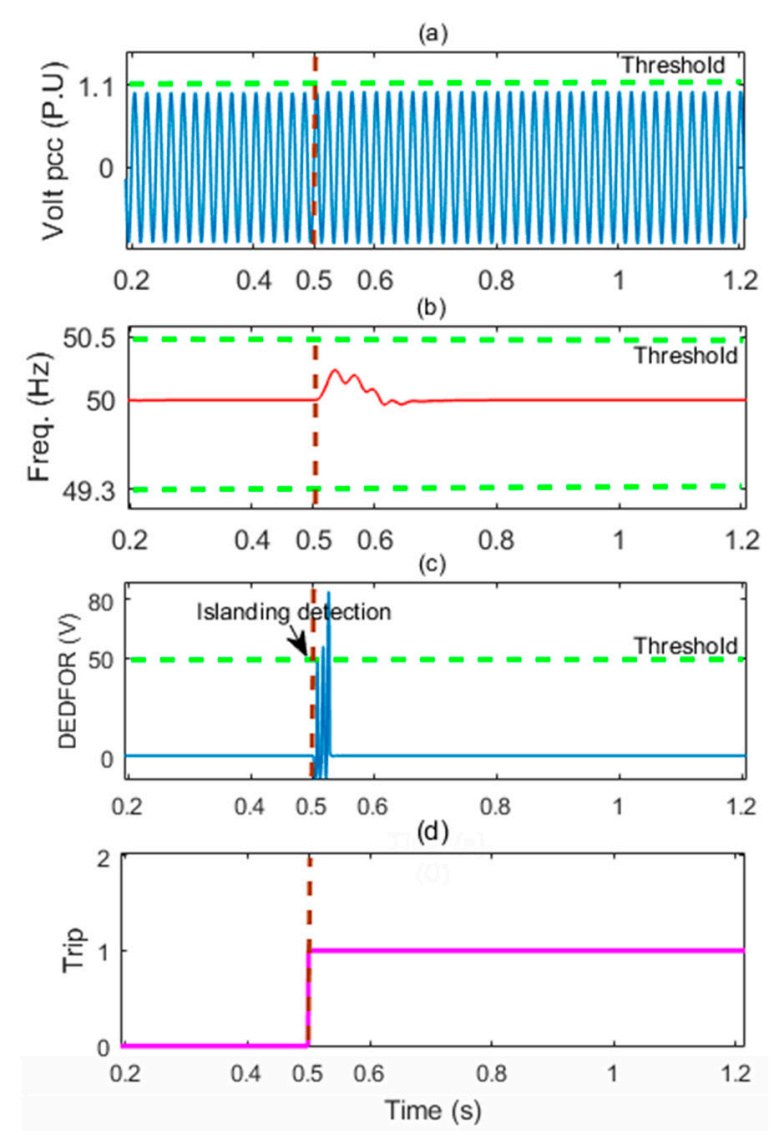

Figure 6. Case 1: (a) voltage at PCC; (b) frequency at PCC; (c) output of the proposed DEDFOR; (d) the trip signal for $\mathrm{CB}$. 


\subsection{Case 2: NDZ Determination}

In real operation, there is always some level of active/reactive power mismatch between the output of DG and load of the power system. An active power mismatch refers to the ratio of active power flow on PCC before islanding condition to the total power generated by the DG while the reactive power mismatch is constant. Similarly, reactive power mismatches can be defined. It should be noted that voltage magnitude $(V)$ and frequency $(f)$ of DGs will not change significantly which makes the islanding detection difficult for over/under voltage or frequency relays. More details regarding the power balance and islanding formulation are available in [51].

In grid connected mode the power mismatch is compensated by the grid, i.e., $\Delta P \neq 0, \Delta Q \neq 0$. When the grid is disconnected, the voltage $(V)$ and frequency $(f=1 / 2 \pi \sqrt{L C})$ will be forced to new values, $\hat{V}, \hat{f}$ :

$$
f^{\prime}=\frac{1}{2 \pi \sqrt{(L+\Delta L) \cdot(C+\Delta C)}}
$$

Considering the pre-islanding frequency, we can write [37]:

$$
\frac{f^{\prime}-f}{f}=\frac{\sqrt{L \cdot C}}{\sqrt{(L+\Delta L) \cdot(C+\Delta C)}}-1
$$

where $f_{\max }$ and $f_{\min }$ are under and over frequency thresholds, respectively.

Given the frequency thresholds, $f_{\min }$ and $f_{\max }$, for $f^{\prime}$ to be within the thresholds and assuming $\Delta L=\Delta C \approx 0$, the following condition must be met:

$$
\left(\frac{f}{f_{\max }}\right)^{2}-1 \leq \frac{\Delta L}{L}+\frac{\Delta C}{C} \leq\left(\frac{f}{f_{\min }}\right)^{2}-1
$$

The relationship between $\Delta L, \Delta C$ and can be derived as:

$$
\Delta Q=V^{2} \cdot\left(\frac{1}{2 \pi \cdot f \cdot(L+\Delta L)}-2 \pi \cdot f \cdot(C+\Delta C)\right)=\frac{Q_{L}}{\frac{1+\Delta L}{L}}-Q_{C} \cdot\left(\frac{1+\Delta C}{C}\right)
$$

Considering $Q_{L}=Q_{C}=\alpha_{f} \cdot P$, Equation (2) can be rewritten in a normalized form as:

$$
\frac{\Delta Q}{P}=\frac{Q_{f}}{\frac{1+\Delta L}{L}}-Q_{f} \cdot\left(\frac{1+\Delta C}{C}\right) \approx-Q_{f} \cdot\left(\frac{\Delta L}{L}+\frac{\Delta C}{C}\right)
$$

where $\alpha_{f}$ is the quality factor.

From Equations (17) to (21) we can write:

$$
\alpha_{f}\left(1-\left(\frac{f}{f_{\min }}\right)^{2}\right) \leq \frac{\Delta Q}{P} \leq \alpha_{f}\left(1-\left(\frac{f}{f_{\max }}\right)^{2}\right)
$$

The same way we can drive the following threshold for voltage:

$$
\left(\frac{V}{V_{\max }}\right)^{2}-1 \leq \frac{\Delta P}{P} \leq\left(\frac{V}{V_{\min }}\right)^{2}-1
$$

where $V_{\max }$ and $V_{\min }$ a are under and over voltage thresholds, respectively. Details of the analysis is available in [37].

In addition, there is a strong relation between $V_{P C C}$ and $P_{D G}$ and $Q_{D G}$ as follows:

$$
S_{D G}-\Delta S=V_{p c c}{ }^{2} / Z_{L}^{*}
$$




$$
\begin{gathered}
P_{D G}-\Delta \mathrm{P}=\operatorname{Real}\left(V_{p c c^{2}} / Z_{L}^{*}\right) \\
Q_{D G}-\Delta \mathrm{Q}=\operatorname{Imag}\left(V_{p c c^{2}} / \mathrm{Z}_{L}^{*}\right)
\end{gathered}
$$

Based on Equations (12) and (25), if $\Delta P$ changes in positive direction, it means $P_{\text {Load }}<P_{D G}$, and voltage will increase after CB1 is opened. On the contrary, in negative power mismatch $\left(P_{\text {Load }}>P_{D G}\right), V_{p c c}$ will decrease. In this case study, several sensitive scenarios with the low active/reactive power mismatch have been tested to evaluate the performance of the proposed method under various power mismatch, ranging from $5 \%$ to $20 \%$.

\subsubsection{Scenario I}

In this scenario, active power mismatch is increased step by step to monitor the voltage, frequency and DEDFOR behavior of the network and companion them. As it is clear from Figure $7 \mathrm{a}, \mathrm{b}$, the changes in voltage and frequency are barely noticeable and cannot be detected by relays. However, the proposed DEDFOR can clearly detect islanding with high accuracy and in less than $8 \mathrm{~ms}$ as shown in Figure 7c.
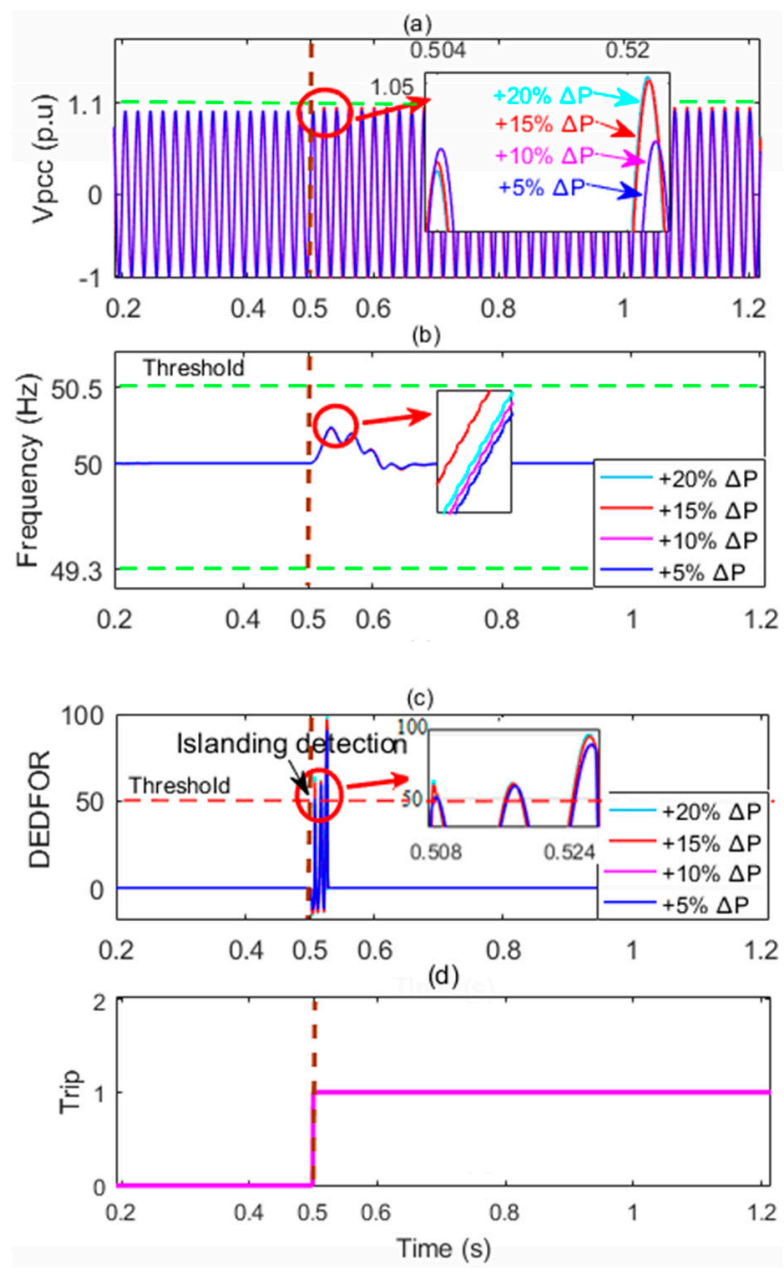

Figure 7. Case2, Scenario I: the results of analysis for increased active power mismatch. (a)Voltage at PCC; (b) frequency at PCC; (c) output of the proposed DEDFOR detector; (d) the trip signal for CB1.

\subsubsection{Scenario II}

In this scenario and in four steps, active power mismatch is decreased to survey the network behavior. The same as the previous scenario, as depicted in Figure $8 \mathrm{a}, \mathrm{b}$ the changes in voltage and frequency are barely noticeable and cannot be detected by relays. By decreasing the active power, the voltage drops at islanding mode in comparison to connected mode. Since the DG tries to control all 
parameters, it is difficult to detect islanding based on the changes in voltage and frequency. However, as depicted in Figure 8c, the DEDFOR algorithm can accurately and efficiently detect the islanding condition under different range of power mismatches.

(a)

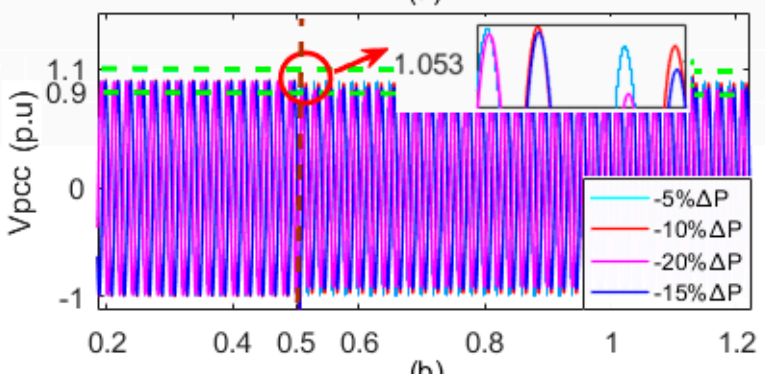

(b)

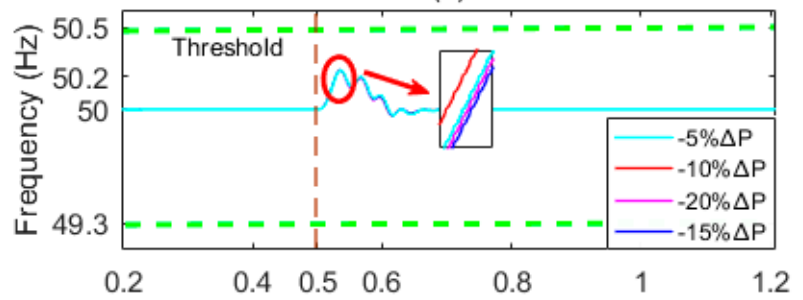

(c)
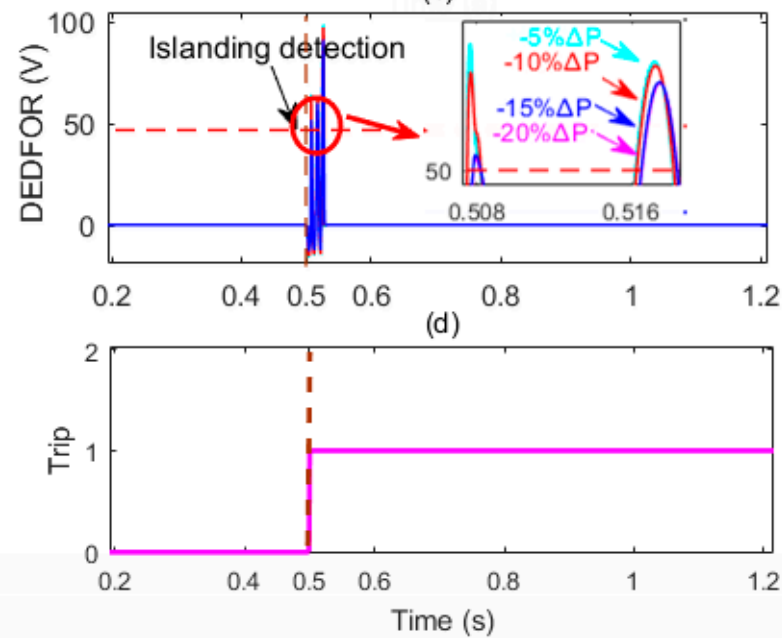

Figure 8. Case2, Scenario II: the results of analysis for decreased active power mismatch, (a)Voltage at PCC; (b) frequency at PCC; (c) output of the proposed DEDFOR detector; (d) the trip signal for CB1.

\subsubsection{Scenarios III, IV}

In these scenarios reactive power mismatch is increased step by step and the performance of the system is analyzed in each part. Figure 9 clearly shows and compares network parameters when reactive power mismatch increased. Although voltage and frequency at PCC have some changes in each case, they cannot be detected by relay. Using DEDFOR islanding condition is accurately detected in less than $17 \mathrm{~ms}$. 

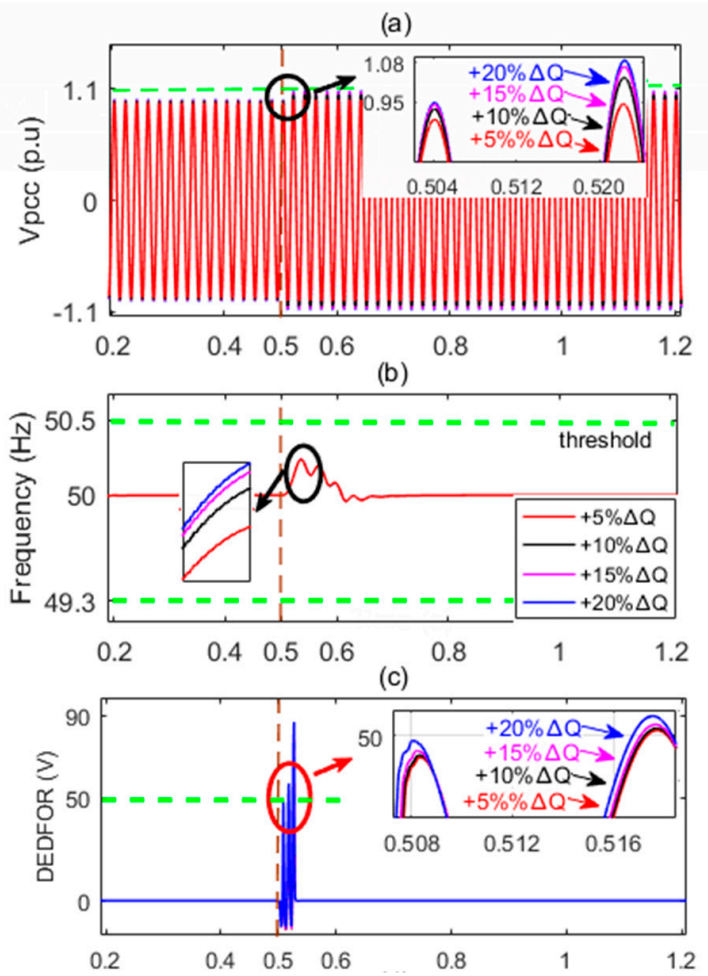

(d)

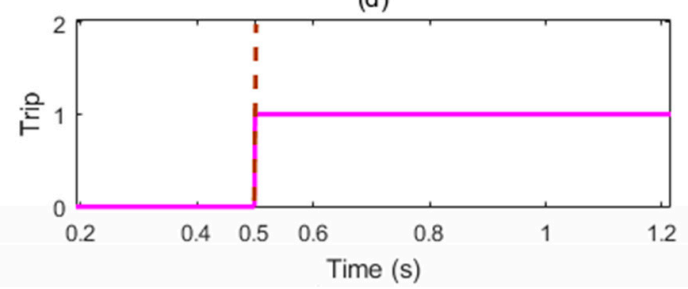

Figure 9. Case2, Scenario III: the results of analysis for increased reactive power mismatch, (a)Voltage at PCC; (b) frequency at PCC; (c) output of the proposed DEDFOR detector; (d) the trip signal for CB1.

A summary of the results is provided in Table 3.

Table 3. Various islanding condition for different power mismatches.

\begin{tabular}{cccc}
\hline Scenarios & Power Mismatch & Different Ranges & Constant Value \\
\hline Scenario I & increased $\% \Delta P$ & $+5 \%,+10 \%,+15 \%,+20 \% \Delta P$ & $100 \% \Delta Q$ \\
\hline Scenario II & decreased $\% \Delta P$ & $-5 \%,-10 \%,-15 \%,-20 \% \Delta P$ & $100 \% \Delta Q$ \\
\hline Scenario III & Increased $\% \Delta Q$ & $+5 \%,+10 \%,+15 \%,+20 \% \Delta Q$ & $100 \% \Delta Q$ \\
\hline Scenario IV & decreased $\% \Delta Q$ & $-5 \%,-10 \%,-15 \%,-20 \% \Delta Q$ & $100 \% \Delta Q$ \\
\hline
\end{tabular}

\subsection{Case 3: Capacitor Switching Condition}

When capacitor banks enter the grid, the reactive power in the grid will change. In this condition, the grid voltage will change similar to islanding condition. Therefore, islanding protection relays or methods should have the ability to distinguish it from the islanding condition to avoid a false trip. In this case study, a large capacitor bank is switched at the PCC at $t=0.5 \mathrm{~s}$ by closing CB2. The results presented in Figure 10 show that the proposed method can successfully separate the islanding condition from capacitor switching with high accuracy. The output of the proposed DEDFOR detector will not reach the predefined threshold which indicates that capacitor switching is not detected at islanding condition. 


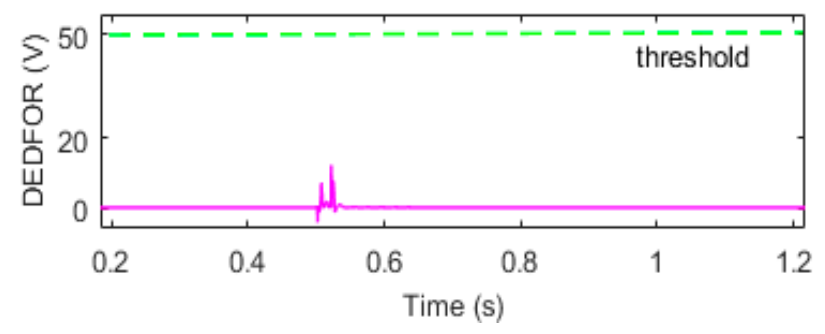

Figure 10. Case 3: Output of the proposed DEDFOR filter under capacitor switching condition.

\subsection{Case 4: Motor Starting}

Dynamic characteristics of the motors require high current at the starting point which lowers the terminal voltage. As the voltage across the load on the transmission line drops, it is usually misinterpreted as an islanding condition. Thus, anti-islanding protection relays should have the ability to distinguish it from islanding conditions. To verify the functionality of the proposed method under a motor starting condition, it is tested under motor driving conditions when CB3 is closed at $t=0.5 \mathrm{~s}$. It can be seen from the results in Figure 11 that the algorithm can accurately and efficiently separate motor starting from the islanding conditions. The output of the proposed DEDFOR detector will not reach the predefined threshold which indicates that capacitor switching is not detected as islanding condition.

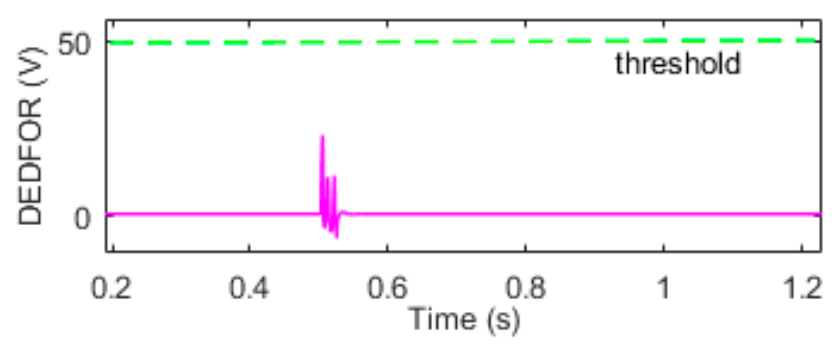

Figure 11. Case 4: Output of the proposed DEDFOR filter under motor starting condition.

\subsection{Case 5: Load Change}

In this case, a sudden load reduction and increase is simulated at $0.5 \mathrm{~s}$ and $1 \mathrm{~s}$, respectively, to survey the network behavior under these changes. As can be seen in Figure 12, both these changes results in some alteration in the output of the proposed detector, however, it will not pass the predefined threshold and accurately separate both scenarios from islanding condition.

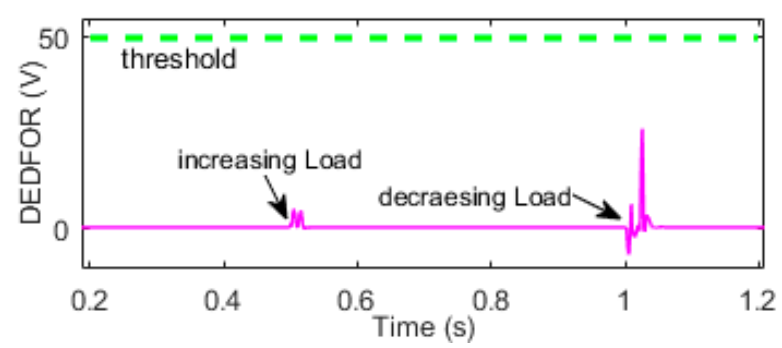

Figure 12. Case 5: Output of the proposed DEDFOR filter under load changes.

Overall, our simulation results have verified the accuracy and efficiency of the proposed method under different operating conditions. Certainly, one of the most important factors in islanding protection is the detection time which is the lowest amount in the proposed method. Actually, the proposed algorithm is faster than other well-known methods used for islanding detection. The average detection rate for the proposed method is less than $10 \mathrm{~ms}$ (minimum $6.09 \mathrm{~ms}$ and 
maximum $17 \mathrm{~ms}$ for detection) which is considerably smaller than other existing methods in the literature such as wavelet transform [42], S-transform [43], and MM [46] with average detection times of 18,26 , and $21 \mathrm{~ms}$, respectively. It results in a low computational burden which makes it suitable for implementation in large-scale power systems. In addition, compared to the passive methods, the NDZ is significantly reduced. In general, any change in the power grid that affects the voltage of load at the PCC can be identified and separated from islanding conditions.

\section{Conclusions}

Unintentional islanding due to grid faults or wrong circuit breaker operations may result in irreparable damages to the system. Therefore, it is necessary to effectively detect the islanding conditions and swiftly disconnect DG from the distribution network within a specified time interval. In this work, an accurate and efficient islanding detection method based on MM is developed and tested on a microgrid with DFIG sources. Proposed method is a signal processing technique which does not need requires huge data transfer and only uses simple math operators with low computational burden. MM is used to highlight the sudden changes in the signals which cannot be detected by existing relays. The proposed method is tested under different operation conditions, including capacitor switching, motor starting, load changes and different active and reactive power mismatch. Simulation results verify the accuracy and efficiency of the proposed method. It is a fast and reliable approach which can detect islanding under $17 \mathrm{~ms}$ with high accuracy. Performance of the proposed method is not affected by changes of the parameters or operation conditions, as shown by the results. It is scalable for large-scale power systems due to its low computational burden and simplicity.

Author Contributions: conceptualization, F.G and H.K. and H.G.; methodology, F.G.; software, B.A.MA.; validation, F.G., B.A.M.A. and H.K.; formal analysis, F.G.; investigation, F.G. and B.A.MA; resources, F.G.; data curation, F.G.; writing—original draft preparation, F.G. and H.K.; writing-review and editing, H.K and H.G.; visualization, F.G.; supervision, H.K., H.G.; project administration, H.K. and H.G.

Funding: This research received no external funding.

Conflicts of Interest: The authors declare no conflict of interest.

\section{Nomenclature}

$\begin{array}{ll}P_{\text {Load }} & \text { Load Real Power } \\ P_{D G} & \text { DG Real Power } \\ \Delta P & \text { Real Power Imbalance Limits } \\ Q_{\text {Load }} & \text { Load Power } \\ Q_{D G} & \text { DG Reactive Power } \\ \Delta Q & \text { Reactive Power Imbalance Limits } \\ V_{p c c} & \text { Voltage at PCC } \\ Z_{S} & \text { Source Impedance } \\ R_{S} & \text { Source Resistance } \\ X_{S} & \text { Source Reactance } \\ L_{S} & \text { Source Inductance } \\ V_{S} & \text { Source Voltage } \\ \mathrm{CB} & \text { Circuit Breaker } \\ \mathrm{RMS} & \text { Root Mean Square } \\ Z_{L} & \text { Load Impedance } \\ R_{L} & \text { Load Resistance } \\ L_{L} & \text { Load Inductance } \\ C_{L} & \text { Load Capacity } \\ Z_{D G} & \text { DG Impedance } \\ R_{D G} & \text { DG Resistance } \\ X_{D G} & \text { DG Reactance }\end{array}$




\section{References}

1. Guo, F.; Wen, C.; Li, Z. Distributed optimal energy scheduling based on a novel PD pricing feedback strategy in smart grid. In Proceedings of the 2015 IEEE 10th Conference on Industrial Electronics and Applications (ICIEA), Auckland, New Zealand, 15-17 June 2015.

2. Elsisi, M.; Soliman, M.; Aboelela, M.A.S.; Mansour, W. Model predictive control of plug-in hybrid electric vehicles for frequency regulation in a smart grid. IET Gener. Transm. Distrib. 2017, 11, 3974-3983. [CrossRef]

3. Wang, Y.; Mao, S.; Nelms, R.M. On hierarchical power scheduling for the macrogrid and cooperative microgrids. IEEE Trans. Ind. Inform. 2015, 11, 1574-1584.

4. Microgrid Exchange Group. DOE Microgrid Workshop Report; The U.S. Department of Energy (DOE): San Diego, CA, USA, 2011.

5. Smith, M.; Ton, D. Key connections: The U.S. department of energy's microgrid initiative. IEEE Power Energy Mag. 2013, 11, 22-27. [CrossRef]

6. Farzin, H.; Fotuhi-Firuzabad, M.; Moeini-Aghtaie, M. Stochastic energy management of microgrids during unscheduled islanding period. IEEE Trans. Ind. Inform. 2017, 13, 1079-1087. [CrossRef]

7. Che, L.; Shahidehpour, M.; Alabdulwahab, A.; Al-Turki, Y. Hierarchical coordination of a community microgrid with AC and DC microgrids. IEEE Trans. Smart Grid 2015, 6, 3042-3051. [CrossRef]

8. Ghanbari, N.; Mokhtari, H.; Bhattacharya, S. Optimizing operation indices considering different types of distributed generation in microgrid applications. Energies 2018, 11, 894. [CrossRef]

9. Han, Y.; Ma, R.; Cui, J. Adaptive higher-order sliding mode control for islanding and grid-connected operation of a microgrid. Energies 2018, 11, 1459. [CrossRef]

10. Zheng, T.; Yang, H.; Zhao, R.; Kang, Y.C.; Terzija, V. Design, evaluation and implementation of an islanding detection method for a micro-grid. Energies 2018, 11, 323. [CrossRef]

11. Jia, K.; Ren, Z.; Li, L.; Xuan, Z.; Thomas, D. High-frequency transient comparison based fault location in distribution systems with DGs. IET Gener. Transm. Distrib. 2017, 11, 4068-4077. [CrossRef]

12. Alaboudy, A.H.K.; Zeineldin, H.H. Islanding detection for inverter-based dg coupled with frequencydependent static loads. IEEE Trans. Power Deliv. 2011, 26, 1053-1063. [CrossRef]

13. Ghalavand, F.; Al-omari, A.; Karegar, H.K.; Karimipour, H. Hybrid islanding detection for ac/dc network using DC-link voltage. In Proceedings of the IEEE International Conference on Smart Energy Grid Engineering (SEGE), Oshawa, ON, Canada, 12-15 August 2018.

14. Issa, W.R.; Abusara, M.A.; Sharkh, S.M. Control of transient power during unintentional islanding of microgrids. IEEE Trans. Power Electron. 2015, 30, 4573-4584. [CrossRef]

15. Salles, D.; Freitas, W.; Vieira, J.C.M.; Venkatesh, B. A practical method for nondetection zone estimation of passive anti-islanding schemes applied to synchronous distributed generators. IEEE Trans. Power Deliv. 2015, 30, 2066-2076. [CrossRef]

16. Cagnano, A.; De Tuglie, E.; Cicognani, L. Prince-Electrical energy systems lab: A pilot project for smart microgrids. Electr. Power Syst. Res. 2017, 148, 10-17. [CrossRef]

17. Cagnano, A.; De Tuglie, E.; Trovato, M.; Cicognani, L.; Vona, V. A simple circuit model for the islanding transition of microgrids. In Proceedings of the IEEE 2nd International Forum on Research and Technologies for Society and Industry Leveraging a better tomorrow (RTSI), Bologna, Italy, 7-9 September 2016.

18. IEEE Standard. 1547-2003-IEEE standard for interconnecting distributed resources with electric power systems. IEEE Stand. Assoc. 2003. [CrossRef]

19. IEEE Standard. 1547-2018-IEEE standard for interconnection and interoperability of distributed energy resources with associated electric power systems interfaces (revision of IEEE Std 1547-2003). IEEE Stand. Assoc. 2018. [CrossRef]

20. Reis, M.V.G.; Barros, T.A.S.; Moreira, A.B.; Paulo, S.N.F.; Ernesto, R.F.; Villalva, M.G. Analysis of the Sandia Frequency Shift (SFS) islanding detection method with a single-phase photovoltaic distributed generation system. In Proceedings of the 2015 IEEE PES Innovative Smart Grid Technologies Latin America (ISGT LATAM), Montevideo, Uruguay, 5-7 October 2015.

21. Reis, M.V.G.; Villalva, M.G.; Barros, T.A.S.; Paulo, S.N.F.; Moreira, A.B.; Ernesto, R.F. Active frequency drift with positive feedback anti-islanding method for a single phase two-stage grid-tied photovoltaic system. In Proceedings of the 2015 IEEE 13th Brazilian Power Electronics Conference and 1st Southern Power Electronics Conference (COBEP/SPEC 2015), Fortaleza, Brazil, 29 November-2 December 2015. 
22. Raza, S.; Mokhlis, H.; Arof, H.; Laghari, J.A.; Wang, L. Application of signal processing techniques for islanding detection of distributed generation in distribution network: A review. Energy Convers. Manag. 2015, 96, 613-624. [CrossRef]

23. Laaksonen, $\mathrm{H}$. Advanced islanding detection functionality for future electricity distribution networks. IEEE Trans. Power Deliv. 2013, 28, 2056-2064. [CrossRef]

24. Lin, Z.; Xia, T.; Ye, Y.; Zhang, Y.; Chen, L.; Liu, Y.; Tomsovic, K.; Bilke, T.; Wen, F. Application of wide area measurement systems to islanding detection of bulk power systems. IEEE Trans. Power Syst. 2013, 28, 2006-2015. [CrossRef]

25. Sun, R.; Centeno, V.A. Wide area system islanding contingency detecting and warning scheme. IEEE Trans. Power Syst. 2014, 29, 2581-2589. [CrossRef]

26. Hosani, M.A.; Qu, Z.; Zeineldin, H.H. Development of dynamic estimators for islanding detection of inverter-based DG. IEEE Trans. Power Deliv. 2015, 30, 428-436. [CrossRef]

27. Kim, J.-H.; Kim, J.-G.; Ji, Y.-H.; Jung, Y.-C.; Won, C.-Y. An islanding detection method for a grid-connected system based on the Goertzel algorithm. IEEE Trans. Power Electron. 2011, 26, 1049-1055. [CrossRef]

28. Jia, K.; Wei, H.; Bi, T.; Thomas, D.W.P.; Sumner, M. An islanding detection method for multi-DG systems based on high-frequency impedance estimation. IEEE Trans. Sustain. Energy 2017, 8, 74-83. [CrossRef]

29. Emadi, A.; Afrakhte, H.; Sadeh, J. Fast active islanding detection method based on second harmonic drifting for inverter-based distributed generation. IET Gener. Transm. Distrib. 2016, 10, 3470-3480. [CrossRef]

30. Galleani, L.; Tavella, P. Robust detection of fast and slow frequency jumps of atomic clocks. IEEE Trans. Ultrason. Ferroelectr. Freq. Control 2017, 64, 475-485. [PubMed]

31. Mazhari, I.; Jafarian, H.; Enslin, J.H.; Bhowmik, S.; Parkhideh, B. Locking frequency band detection method for islanding protection of distribution generation. IEEE J. Emerg. Sel. Top. Power Electron. 2017, 5, 1386-1395. [CrossRef]

32. Sun, Q.; Guerrero, J.M.; Jing, T.; Vasquez, J.C.; Yang, R. An islanding detection method by using frequency positive feedback based on FLL for single-phase microgrid. IEEE Trans. Smart Grid 2017, 8, 1821-1830. [CrossRef]

33. Reigosa, D.; Blanco, C.; Guerrero, J.M.; Briz, F. Evaluation of high frequency signal injection islanding detection based methods under non-linear-loads scenarios. In Proceedings of the 2016 IEEE Energy Conversion Congress and Exposition (ECCE), Milwaukee, WI, USA, 18-22 September 2016.

34. Gu, C.J.; Wei, H.S.; Jia, K.; Bi, T.S.; Liu, B.H. Positive- and negative-sequence control strategy of grid-connected PV systems under balanced and unbalanced voltage sags. In Proceedings of the 12th IET International Conference on AC and DC Power Transmission (ACDC), Beijing, China, 28-29 May 2016.

35. Hamzeh, M.; Rashidirad, N.; Sheshyekani, K.; Afjei, E. A new islanding detection scheme for multiple inverter-based dg systems. IEEE Trans. Energy Convers. 2016, 31, 1002-1011. [CrossRef]

36. Zeineldin, H.H., Jr. Performance of the OVP/UVP and OFP/UFP method with voltage and frequency dependent loads. IEEE Trans. Power Deliv. 2009, 24, 772-778. [CrossRef]

37. Ye, Z.; Kolwalkar, A.; Zhang, Y.; Du, P.; Walling, R. Evaluation of anti-islanding schemes based on nondetection zone concept. IEEE Trans. Power Electron. 2004, 19, 1171-1176. [CrossRef]

38. Yin, J.; Diduch, C.P.; Chang, L. Islanding detection using proportional power spectral density. IEEE Trans. Power Deliv. 2008, 23, 776-784. [CrossRef]

39. Liu, N.; Aljankawey, A.; Diduch, C.; Chang, L.; Su, J. Passive islanding detection approach based on tracking the frequency-dependent impedance change. IEEE Trans. Power Deliv. 2015, 30, 2570-2580. [CrossRef]

40. Samui, A.; Samantaray, S.R. Wavelet singular entropy-based islanding detection in distributed generation. IEEE Trans. Power Deliv. 2013, 28, 411-418. [CrossRef]

41. Hartmann, N.B.; dos Santos, R.C.; Grilo, A.P.; Vieira, J.C.M. Hardware implementation and real time evaluation of an ANN-based algorithm for anti-islanding protection of distributed generators. IEEE Trans. Ind. Electron. 2017, 65, 5051-5059. [CrossRef]

42. Arachchige, L.W.; Rajapakse, A. A pattern recognition approach for detecting power islands using transient signals_Part I: Design and implementation. In Proceedings of the 2011 IEEE Power and Energy Society General Meeting, Detroit, MI, USA, 24-29 July 2011.

43. El-Arroudi, K.; Joos, G.; Kamwa, I.; McGillis, D.T. Intelligent-Based approach to islanding detection in distributed generation. IEEE Trans. Power Deliv. 2007, 22, 828-835. [CrossRef] 
44. Khodaparastan, M.; Vahedi, H.; Khazaeli, F.; Oraee, H. A novel hybrid islanding detection method for inverter-based DGs using SFS and ROCOF. IEEE Trans. Power Deliv. 2017, 32, 2162-2170. [CrossRef]

45. Dhar, S.; Dash, P.K. Harmonic profile injection-based hybrid active islanding detection technique for PV-VSC-based microgrid system. IEEE Trans. Sustain. Energy 2016, 7, 1473-1481. [CrossRef]

46. Azim, R.; Li, F.; Xue, Y.; Starke, M.; Wang, H. An islanding detection methodology combining decision trees and Sandia frequency shift for inverter-based distributed generations. IET Gener. Trans. Distrib. 2017, 11, 4104-4113. [CrossRef]

47. Murugesan, S.; Murali, V.; Daniel, S.A. Hybrid analyzing technique for active islanding detection based on d-axis current injection. IEEE Syst. J. 2017, 1-10. [CrossRef]

48. Pena, R.; Clare, J.C.; Asher, G.M. Doubly fed induction generator using back-to-back PWM converters and its application to variable-speed wind-energy generation. IEE Proc. Electr. Power Appl. 1996, 143, 231-241. [CrossRef]

49. Arguence, O.; Raison, B.; Cadoux, F. Comments on "impact of load frequency dependence on the NDZ and performance of the SFS islanding detection method". IEEE Trans. Ind. Electron. 2017, 64, 7277-7279. [CrossRef]

50. Heier, S. Grid Integration of Wind Energy: Onshore and Offshore Conversion System; Wiley: Hoboken, NJ, USA, 2014.

51. Bayat, H.; Yazdani, A. A power mismatch elimination strategy for an MMC-based photovoltaic system. IEEE Trans. Energy Convers. 2018, 33, 1519-1528. [CrossRef]

(C) 2018 by the authors. Licensee MDPI, Basel, Switzerland. This article is an open access article distributed under the terms and conditions of the Creative Commons Attribution (CC BY) license (http:/ / creativecommons.org/licenses/by/4.0/). 